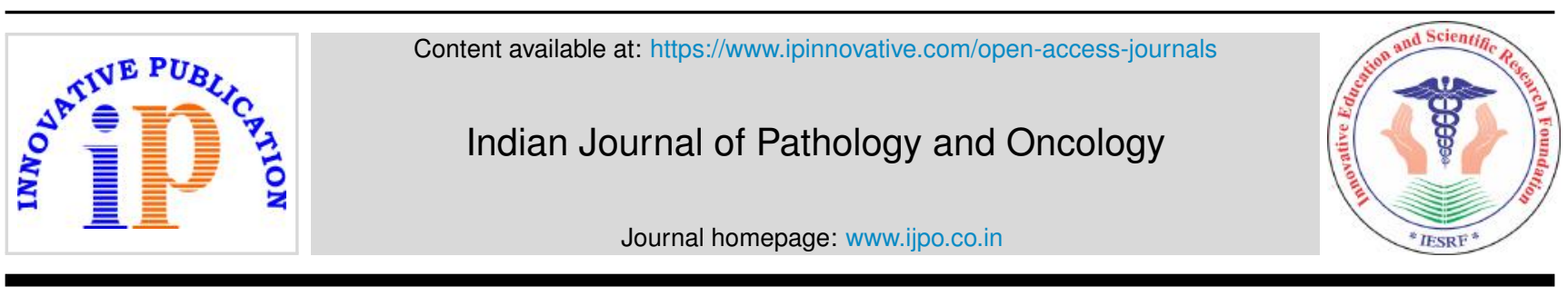

Original Research Article

\title{
Effect of room temperature and refrigerated storage on automated hematological parameters
}

\author{
Sree Ramya $\mathrm{D}^{\mathbf{1}}$, Nagalakshmi Vijayambika $\mathbf{J}^{1, *}$, Eswari $\mathbf{V}^{\mathbf{1}}$ \\ ${ }^{1}$ Dept. of Pathology, Meenakshi Medical College Hospital Research Institute, Enathur, Tamil Nadu, India
}

\section{A R T I C L E I N F O}

\section{Article history:}

Received 22-05-2020

Accepted 04-06-2020

Available online 19-11-2020

Keywords:

Hematological parameters

Refrigerated storage

Room temperature

\begin{abstract}
A B S T R A C T
Background: For evaluating and monitoring of both inpatients and outpatients, complete blood count is one of the commonly performed investigations but at times it is challenging to evaluate all the blood samples on the collected day due to various factors like manpower shortages, weekends, and a single cell counter. Inspite of all these conditions we need to provide accurate report to patients. Hematology results are often influenced by the time between blood sampling and measurement as well as the storage conditions during sample delivery. This is because the hematological elements have limited stability in EDTAanticoagulated blood. The stability of hematological parameters has improved after the anticoagulated blood is refrigerated.

Aim: The aim is to investigate the effect of room temperature and refrigerated storage on complete blood counts and peripheral blood smear on automated hematological parameters.

Materials and Methods: Blood samples were collected from 100 patients. Hematological parameters like Hemoglobin, PCV, MCV, MCH, MCHC, Platelet count, Red blood cell and White blood cell count were analyzed in room temperature storage and refrigerated storage at $40 \mathrm{c}$ for $24 \mathrm{hrs}$ using automated hematology analyzer. Peripheral blood smear from samples stored at room temperature and at $40 \mathrm{C}$ in refrigerators for 24hrs were also examined.

Results: The study revealed RBC count and Hemoglobin were unaffected by storage at room temperature and refrigerated storage. Whereas MCV showed significant increase with storage at room temperature and WBC showed decrease in count with storage at room temperature that is preserved by refrigeration.

(C) This is an open access article distributed under the terms of the Creative Commons Attribution License (https://creativecommons.org/licenses/by/4.0/) which permits unrestricted use, distribution, and reproduction in any medium, provided the original author and source are credited.
\end{abstract}

\section{Introduction}

Complete blood count and Peripheral blood smear are the most common and routinely done investigations, which will give essential information about numerous diseases. The stability of the parameters is limited in samples of EDTA ${ }^{1}$ anticoagulated blood. Refrigerated storage of collected samples at $4^{0} \mathrm{C}$ maintains the stability of hematological parameters. ${ }^{2}$

Therefore, this study provides a quantitative data and peripheral blood smear changes for blood sample stored in room temperature and in fixed temperature $4^{0} \mathrm{C}$, which is helpful in maintaining the accuracy of hematological

\footnotetext{
* Corresponding author.

E-mail address: j.ammu40@gmail.com (N. Vijayambika J).
}

parameters whenever there is an inevitable delay in evaluation after collection of samples. This method is not only simple and inexpensive but also improves the quality and accuracy of the final report.

\section{Aims and Objectives}

This study was carried out to evaluate the changes in hematological parameters and peripheral blood smear of samples stored at room temperature and refrigeration at $4^{0} \mathrm{C}$ on automated hematological analyzer. 


\section{Materials and Methods}

Blood samples from outpatients and inpatients of all the age groups with no gender discrimination were randomly selected for complete blood counts and peripheral smear examination in the study. Under standardized aseptic conditions $3 \mathrm{ml}$ of venous blood sample is collected in EDTA coated tubes. Shenzhen Mindray five part analyzer is used in determining the WBC, RBC and Platelet counts based on the Electrical impedance method, and colorimetric method for Hemoglobin. Leishman's stain is used for staining the peripheral blood smear. Sample is mixed by gently rolling the tube to ensure good cellular distribution and to minimize artifacts.

\subsection{Room temperature storage}

Fifty blood samples were analyzed at $\mathrm{Ohr}$ on an automated 5part differential for complete hemogram as baseline measurements and a blood smear is prepared. Later the specimen was stored at room temperature and reanalyzed for all parameters including blood smear after $24 \mathrm{hrs}$.

\subsection{Refrigerated storage}

Fifty blood samples were analyzed at $0 \mathrm{hr}$ on an automated 5 part differential for complete hemogram as baseline measurements and peripheral blood smear is prepared. Later the specimen was stored at $4^{0} \mathrm{C}$ in a temperature monitored refrigerator for $24 \mathrm{hrs}$. The samples were re-evaluated for hematological parameters and peripheral blood smear after $24 \mathrm{hrs}$ by bringing the samples to settle at room temperature for 30mins.

\subsection{Study area}

This study was authorized and executed in Department of Pathology at Meenakshi Medical College Hospital and Research Institute.

\subsection{Statistical analysis}

Statistical analysis was conducted in excel (Microsoft office). Results were determined by the SSPS software system. $\mathrm{P}<0.05$ was considered for significant result. Baseline values were taken as $100 \%$ and were compared with the remaining hour's interval values.

\section{Results}

All the results of our present study were shown in tables. Table 1 showing results of complete blood counts in room temperature. Table 2 showing results of complete blood counts in refrigerated temperature.

\subsection{Stability of hemoglobin and RBC counts}

There is no statistical significance in the variation of mean hemoglobin values and mean RBC counts of samples stored at room temperature and refrigeration at $4^{0} \mathrm{C}$.

\subsection{Stability of $W B C$}

The changes in the stability of WBC counts were observed in both the samples stored at room temperature and refrigerated temperature, but the changes observed from refrigerated samples are less therefore stability is better maintained in refrigeration. The statistical significance is high $(\mathrm{p}=0.00001)$ in blood samples of room temperature which is reduced with refrigerated temperature $(\mathrm{p}=0.0006)$ thus maintaining the stability.

\subsection{Stability of platelets}

There is statistical significance $(\mathrm{p}<0.0001)$ in the difference between the mean values of room temperature at $0 \mathrm{hrs}$ and $24 \mathrm{hrs}$, in contrast the platelet stability is retained in refrigerated temperature.

\subsection{Stability of $M C V$ and $M C H C$}

At room temperature there is increase in the mean value of $\mathrm{MCV}$ and a decrease in the mean value of $\mathrm{MCHC}$ with statistical significance $(\mathrm{p}<0.0005)$ which are stabilized with refrigerated temperature $(\mathrm{p}=0.127)$.

Peripheral smear study: Direct smears made at $0 \mathrm{hr}$ were considered as controls. There were no significant morphological artifacts in 50 blood smears made from refrigerated storage samples whereas the 50 blood smears smeared from room temperature stored samples showed significant morphological artifacts. The changes were different among various cells, the artifacts ranged from crenated RBCs to degenerative changes like vacuolation, degranulation, bleb formation in WBCs, swelling and aggregation in platelets. Details were shown below in pie chart1 to pie chart 4 .

The cytoplasmic changes in WBCs include numerous clear vacuoles, unequal distribution of granules with discontinuous cell membrane. ${ }^{1}$ Granularity is increased in neutrophils resembling toxic granules, misleading the final pathological diagnosis. Nuclear changes such as lobulations, pyknosis, smudging and vacuoles were also observed.

\section{Discussion}

In routine clinical and hematology laboratory practice, a frequently encountered scenario is delay in the sample analysis due to numerous circumstances such as sample collection in camps or transportation delay, exposure of the samples to high temperature during transport and increase in waiting time with only one dedicated cell analyzer in 
Table 1: Results of blood samples stored at Room temperature

\begin{tabular}{|c|c|c|c|c|}
\hline & & Number of samples & Mean values & $P$ values \\
\hline \multirow[t]{2}{*}{ Pair 1} & WBC fresh & 50 & 8900.00 & $<10^{-15}$ \\
\hline & WBC $24 \mathrm{hrs}$ & 50 & 8356.00 & \\
\hline \multirow[t]{2}{*}{ Pair 2} & RBC fresh & 50 & 4.1700 & 0.000 \\
\hline & RBC 24hrs & 50 & 4.0762 & \\
\hline \multirow[t]{2}{*}{ Pair 3} & HB fresh & 50 & 10.684 & 0.888 \\
\hline & HB 24hrs & 50 & 10.680 & \\
\hline \multirow[t]{2}{*}{ Pair 4} & PCV fresh & 50 & 34.02 & 0.000 \\
\hline & PCV 24hrs & 50 & 36.12 & \\
\hline \multirow[t]{2}{*}{ Pair 5} & MCV fresh & 50 & 85.42 & 0.002 \\
\hline & MCV 24hrs & 50 & 87.28 & \\
\hline \multirow[t]{2}{*}{ Pair 6} & $\mathrm{MCH}$ fresh & 50 & 27.06 & 0.000 \\
\hline & MCH 24hrs & 50 & 26.30 & \\
\hline \multirow[t]{2}{*}{ Pair 7} & MCHC fresh & 50 & 31.24 & 0.000 \\
\hline & MCHC 24hrs & 50 & 29.88 & \\
\hline \multirow[t]{2}{*}{ Pair 8} & PC fresh & 50 & 2.47394 & 0.036 \\
\hline & PC 24hrs & 50 & 2.6160 & \\
\hline
\end{tabular}

Table 2: Results of blood samples stored at $4^{0} \mathrm{C}$ temperature

\begin{tabular}{|c|c|c|c|c|}
\hline & & Number of samples & Mean values & $P$ values \\
\hline \multirow[t]{2}{*}{ Pair 1} & WBC fresh & 50 & 9028.00 & 0.000 \\
\hline & WBC $24 \mathrm{hrs}$ & 50 & 8812.00 & \\
\hline \multirow[t]{2}{*}{ Pair 2} & RBC fresh & 50 & 4.3920 & 0.682 \\
\hline & RBC 24hrs & 50 & 4.3964 & \\
\hline \multirow[t]{2}{*}{ Pair 3} & $\mathrm{HB}$ fresh & 50 & 12.462 & 0.192 \\
\hline & HB 24hrs & 50 & 12.482 & \\
\hline \multirow[t]{2}{*}{ Pair 4} & PCV fresh & 50 & 39.24 & 0.083 \\
\hline & PCV 24hrs & 50 & 39.42 & \\
\hline \multirow[t]{2}{*}{ Pair 5} & MCV fresh & 50 & 89.32 & 0.127 \\
\hline & MCV 24hrs & 50 & 89.68 & \\
\hline \multirow[t]{2}{*}{ Pair 6} & $\mathrm{MCH}$ fresh & 50 & 29.28 & 0.666 \\
\hline & MCH 24hrs & 50 & 29.34 & \\
\hline \multirow[t]{2}{*}{ Pair 7} & MCHC fresh & 50 & 31.48 & 0.213 \\
\hline & MCHC 24hrs & 50 & 31.18 & \\
\hline \multirow[t]{2}{*}{ Pair 8} & PC fresh & 50 & 2.59900 & 0.288 \\
\hline & PC 24hrs & 50 & 2.6158 & \\
\hline
\end{tabular}

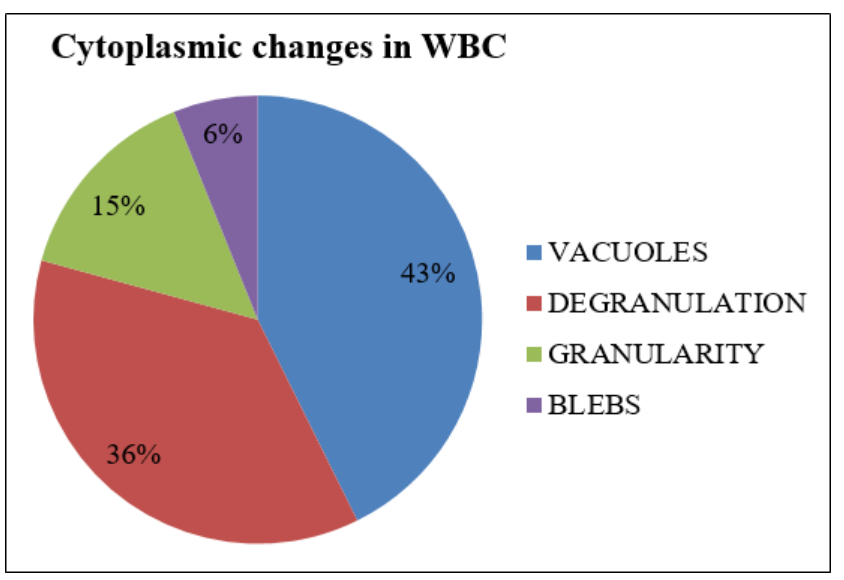

Chart 1: Cytoplasmic changes in WBC

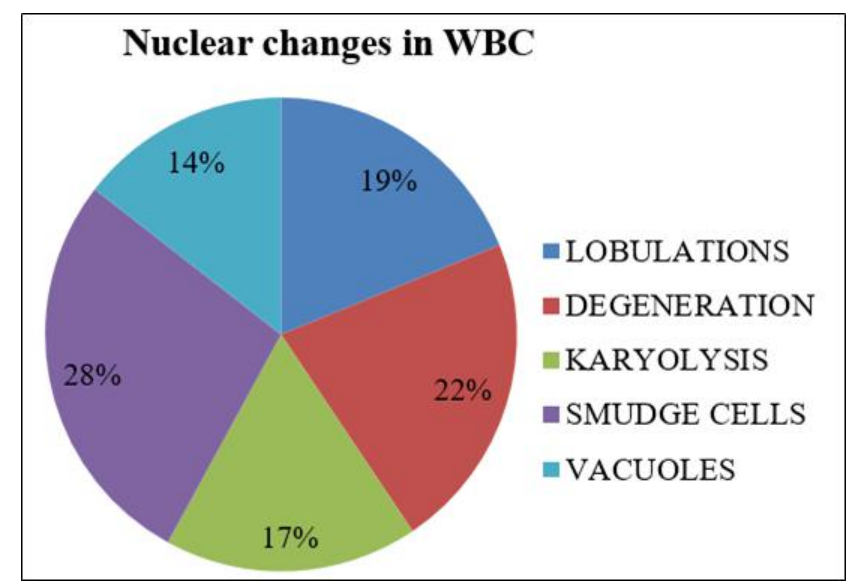

Chart 2: Nuclear changes in WBC 


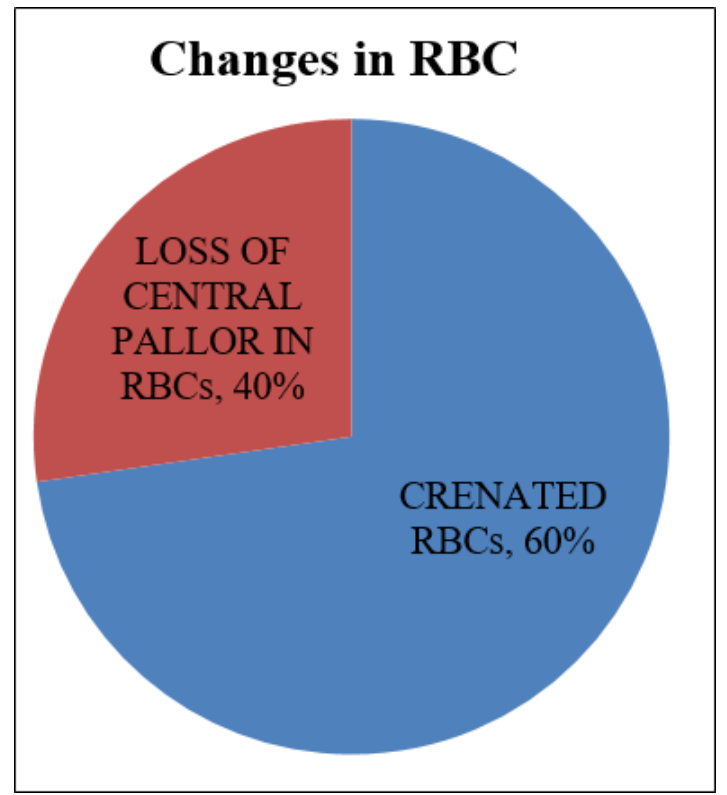

Chart 3: Changes in RBC

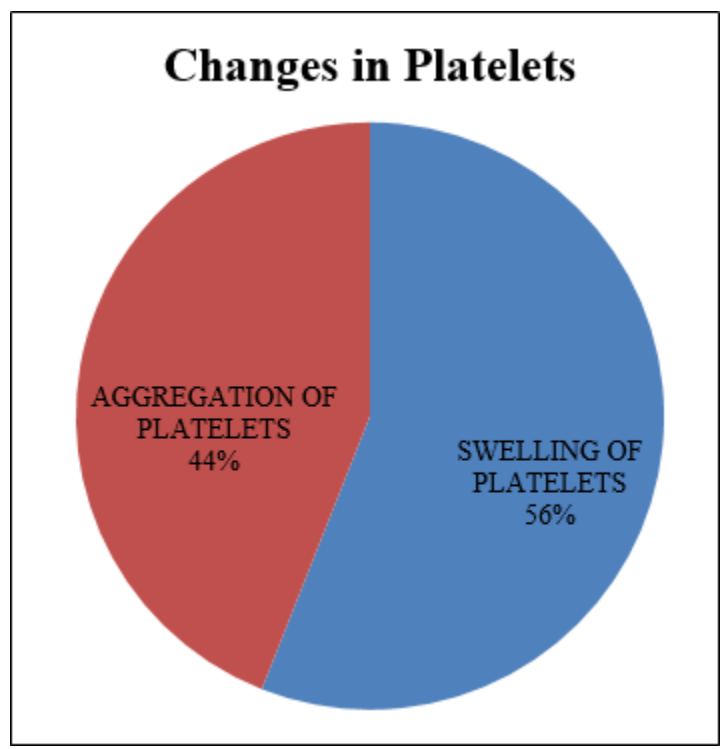

Chart 4: Changes in platelets

the laboratory. Other variables like anticoagulants, storage temperature also influence hematological parameters and blood smear study. In order to give an accurate final report to the patient it is essential to know the influence of climatic conditions on the hematological parameters mainly in tropical areas. ${ }^{3-5}$

Ideally, hematologic parameters should be analyzed immediately after collection. If any delay is predicted, refrigeration at $4^{0} \mathrm{C}$ is optimal. When blood is stored at $<2^{0} \mathrm{C}$, there is freezing injury to $\mathrm{RBCs}$ which causes hemolysis and if it is stored at $>6^{0} \mathrm{C}$, overgrowth of unspecified bacteria is seen. ${ }^{4-6}$

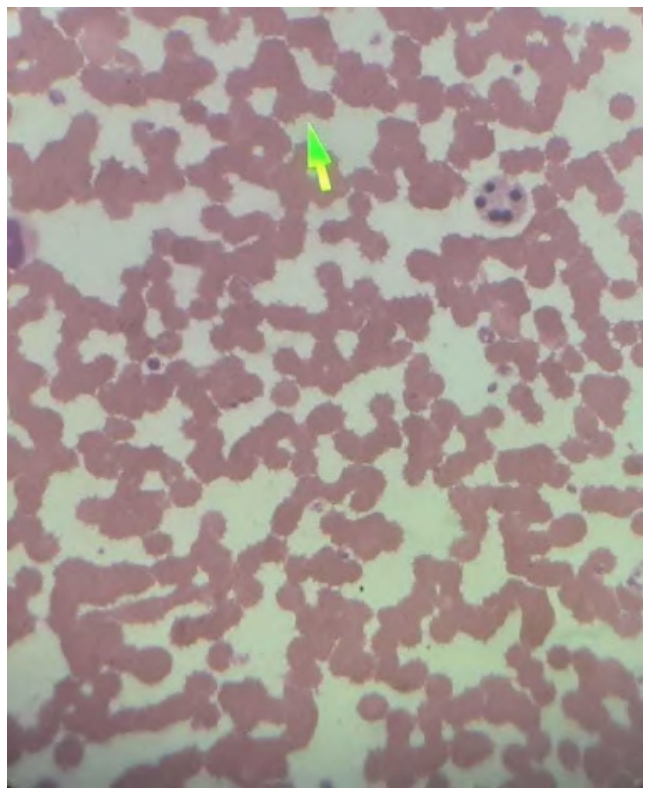

Fig. 1: Leishman stain (100 x Cytoplasmic and nuclear vacuole formation in WBCs

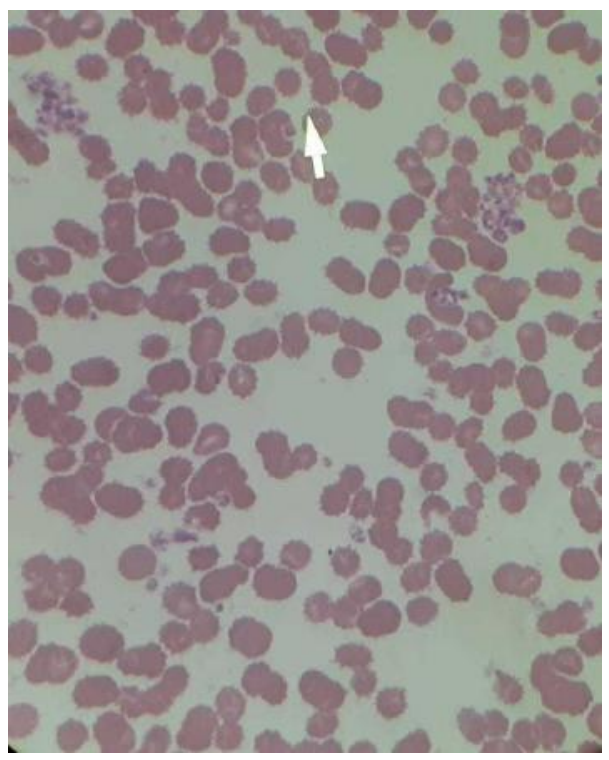

Fig. 2: Leishman stain $(100 \mathrm{x}$ Crenated RBCs and Platelet aggregations

In this study, blood samples stored in monitored refrigeration at $4^{0} \mathrm{C}$ for 24 hours duration show improved stability in most of blood component parameters ${ }^{3}$ and stability of WBC is also increased. ${ }^{7,8}$

Imeri et al. also found consistency of hematological parameters $\mathrm{RBC}$ counts and hemoglobin levels at room temperature and even at $4^{0} \mathrm{C}$ refrigerated storage. ${ }^{7}$ Highly significant decrease in WBC count was noted at room temperature and this reduction in count was corrected 


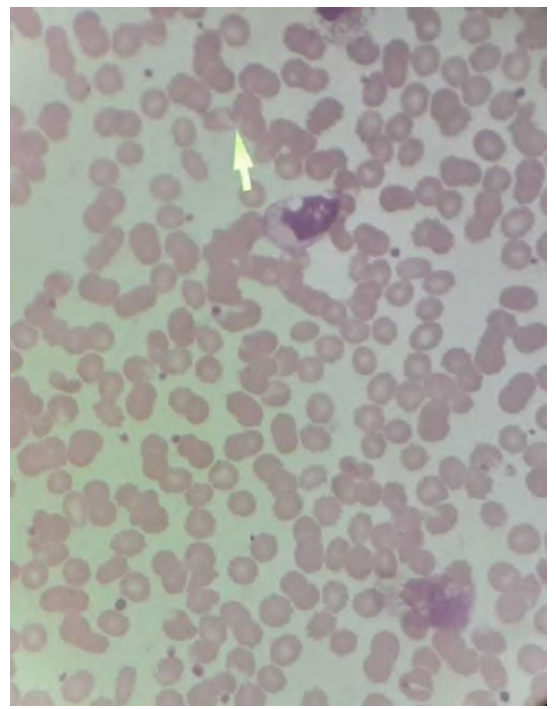

Fig. 3: Leishman stain (100 x Smudge cell in WBCs

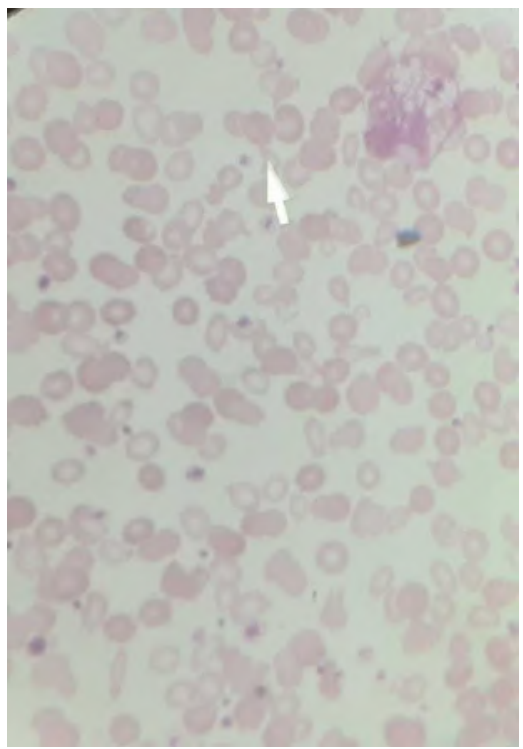

Fig. 4: Leishman stain (100 x nuclear karyolysis and cytoplasmic granulation in WBCs

in samples stored at $4^{0} \mathrm{C}$ refrigerated temperature. ${ }^{2}$ The significant decrease in WBC count in room temperature samples was mainly due to morphological artifacts in cytoplasm like degranulation caused by release of secretory granules, vacuolation, degeneration, less frequently blebs and nuclear degeneration like karyolysis in neutrophils, lobulations in lymphocytes. In contrast, the light scatter properties and morphology of WBCs is stabilized by refrigeration at $4^{0} \mathrm{C}$, which improved the counts.

$\mathrm{MCV}$ is increased with storage at room temperature due to crenated RBCs. Thus our finding is similar to the study of Brent L. Wood et al.

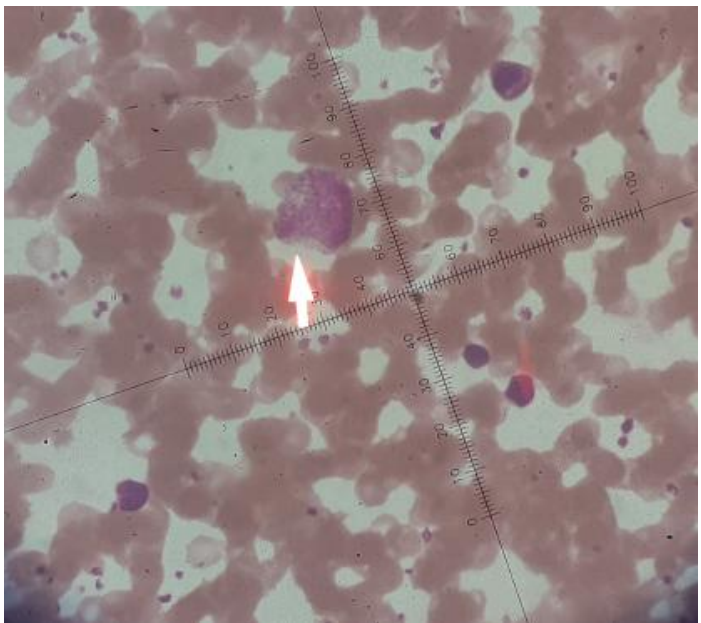

Fig. 5: Leishman stain (100 x nuclear degeneration of WBCs

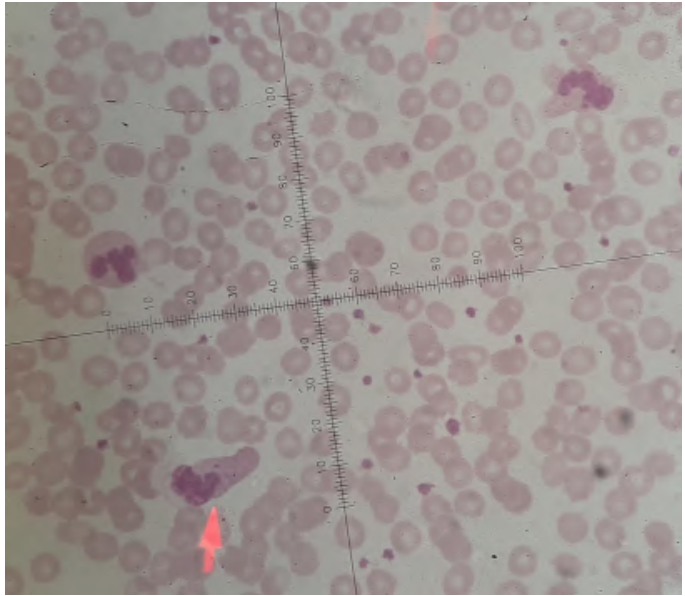

Fig. 6: Leishman stain (100 x Cytoplasmic degranulation of WBCs

Smears from samples at room temperature show aggregation and swelling of the platelets accounting for low platelet count and platelet volume. Our study shows statistically significant mean values which are concordant with other studies. $^{8}$ Platelet stability is maintained with refrigeration of samples. To avoid misreading as pseudothrombocytopenia it is recommended to refrigerate the sample in case of delay to maintain accuracy of the values.

Previous studies on peripheral blood smear cited morphological changes began beyond $2 \mathrm{hrs}$ and are prominent after 6 hours. ${ }^{9}$ We observed pronounced degenerative changes in smear of room temperature stored samples, which may be misinterpreted as pathological findings and thus leading to incorrect diagnosis. However by storing the blood samples at $4^{0} \mathrm{C}$ we could maintain the cell morphology.

The degenerative change first observed was vacuolation in cytoplasm followed by degranulation, hairy projection, 
and bleb formation. In WBCs, nuclear changes like karyolysis, vacuolation, lobulations and smudge cells were observed. Due to increase in osmotic fragility RBCs were crenated. Swelling and aggregations of platelets were observed similar to previous studies. ${ }^{9}$

\section{Conclusion}

For interpreting complete blood count and peripheral blood smear in particular, $24 \mathrm{hr}$ blood sample at room temperature storage is unsatisfactory. Hence refrigeration of EDTA blood samples at $4^{0} \mathrm{c}$ is recommendedwhenever there is a predictable delay in the interpretation of the sample, ${ }^{10,11}$ in order to provide an accurate report.

\section{Abbreviations}

RBC- Red Blood Cells; WBC- White Blood Cells; PC- Platelet count; MCV- Mean Corpuscular Volume; MCH- Mean Corpuscular Hemoglobin; MCHC- Mean Corpuscular Hemoglobin; EDTAEthylenediaminetetraacetic acid.

\section{Source of Funding}

Nil.

\section{Conflict of Interest}

None.

\section{References}

1. Vajpayee N, Graham SS, Bem S. Basic Examination of Blood and Bone Marrow. In: Henry's Clinical Diagnosis and Management By Laboratory Methods. India: Saunders; 2007. p. 476.

2. Wood BL, Andrews J, Miller S, Sabath DE. Refrigerated storage improves the stability of the complete blood cell count and automated differential. Am J Clin Pathol. 1999;112(5):687-95.

3. Turhan T, Sezer S, Yücel C, Koca Y. Effects of Storage Conditions on Complete Blood Cell Count Parameters. Turk J Biochem.
2011;36(2):165-74.

4. Hussain S, Mehmood R, Arshad FA, Khan S. Evaluation and Comparison of Stability and Reliability of CBC Parameters Determined by Using Automatic Celltac G MEK-9100 Hematology Analyzer during Extended Storage at $4^{\circ} \mathrm{C}$. J Clin Res Bioeth. 2018;9(2).

5. Gunawardena D, Jayaweera S, Madhubhashini G, Lokumarakkala DD, Senanayake SJ. Reliability of Parameters of Complete Blood Count With Different Storage Conditions. J Clin Lab Analy. 2017;31(2):e22042.

6. Buttarello M. Quality specification in haematology: the automated blood cell count. Clin Chim Acta. 2004;346(1):45-54.

7. Imeri F, Herklotz R, Risch L, Arbetsleitner C, Zerlauth M, Risch GM, et al. Stability of hematological analytes depends on the hematology analyser used: A stability study with Bayer Advia 120, Beckman Coulter LH 750 and Sysmex XE 2100. Clin Chim Acta. 2008;397(12):68-71.

8. Tendulkar A, Jain P, Gujral S, Tambe M, Kenjale R, Ganesh B. Stability of Selected Hematological Parameters in Stored Blood Samples. J Cell Sci Ther. 2015;6(5):1-5.

9. Narasimha A, Kumar H, Prasad CSBR. Anticoagulant induced artefacts in peripheral blood smears. Indian J Hematol Blood Transfus. 2008;24(2):43-8

10. Basu D, Veluru H. A Study of Storage Related Changes and Effect of Refrigeration on Hematological Parameters and Blood Cell Morphology in EDTA Anticoagulated Blood. Ann Pathol Lab Med. 2019;6(5):289-96.

11. Furlanello T, Tasca S, Caldin M, Carli E, Patron C, Tranquillo M, et al Artifactual changes in canine blood following storage, detected using the ADVIA 120 hematology analyzer. Vet Clin Pathol. 2006;35(1):426

\section{Author biography}

Sree Ramya D, Post Graduate

Nagalakshmi Vijayambika J, Assistant Professor

Eswari V, Professor and Head

Cite this article: Ramya D S, Vijayambika J N, Eswari V. Effect of room temperature and refrigerated storage on automated hematological parameters. Indian J Pathol Oncol 2020;7(4):625-630. 